\title{
Laparoscopic vs open colorectal cancer surgery in elderly patients: short- and long- term outcomes and predictors for overall and disease-free survival
}

Sicheng Zhou, Xuewei Wang, Chuanduo Zhao, Qian Liu, Haitao Zhou, Zhaoxu Zheng, Zhixiang Zhou,

Xishan Wang and Jianwei Liang ${ }^{*}$ (D)

\begin{abstract}
Background: Colorectal cancer is common in elderly patients. Laparoscopy is widely used to approach this kind of disease. This study was to examine short-term outcomes and long-term survival for laparoscopic and open surgery in elderly patients with colorectal cancer.

Methods: From January 2007 to December 2018, patients with colorectal cancer older than 80 operated at China National Cancer Center were included in the study. Propensity score matching (PSM) was used to minimize the adverse effects. The clinical data between open and laparoscopic surgery was compared, and the effect of factors on overall survival (OS) and disease-free survival (DFS) was analyzed by Cox proportional hazard model.

Results: Ninety-three pairs were selected after PSM. Patients in laparoscopic group had less intraoperative blood loss, postoperative complications, time to first flatus, time to oral feeding, postoperative hospital stay, and higher retrieved lymph node $(P<0.05)$. The OS and DFS rates were similar $(P>0.05)$, besides the CEA level, III/IV stage, and perineural invasion were independent predictors of survival $(P<0.05)$.
\end{abstract}

Conclusion: In elderly patients with colorectal cancer, laparoscopic surgery had better short-term outcomes than open surgery. CEA level, III/IV stage, and perineural invasion were reliable predictors for OS and DFS.

Keywords: Colorectal cancer, Open surgery, Laparoscopic surgery, Surgical outcomes, Elderly patients

\section{Introduction}

According to the Globocan 2012 database of the World Cancer Research Centre, the incidence of colorectal cancer in those over 75 years old in China is approximately 78,200 every year and it accounted for $18.08 \%$ of the global incidence [1]. Laparoscopic technique for colorectal cancer has been widely applied in clinical practice due to its advantages of small incision, quick recovery, and shorter hospitalization compared with open surgery [2-4]. Meanwhile, its short-term results and long-term efficacy have been confirmed by a series of a large sample, multicenter randomized controlled studies [5-8]. However,

\footnotetext{
* Correspondence: liangjw@163.com

Department of Colorectal Surgery, National Cancer Center/National Clinical Research Center for Cancer/Cancer Hospital, Chinese Academy of Medical Sciences and Peking Union Medical College, Beijing 100021, China
}

there are few literature on whether elderly patients with colorectal cancer can also benefit from laparoscopic surgery [9-12]. Therefore, we designed a single-center and propensity score-matched analysis to investigate the short-term outcomes and survival rates of laparoscopic and open colorectal surgery, as well as the reliable predictors for OS and DFS in elderly patients with colorectal cancer.

\section{Material and methods \\ Patients}

After approved by the ethics committee of Cancer Hospital, Chinese Academy of Medical Sciences (NCC 2017-YZ-026, Oct 17,2017$)$, all curatively operated colorectal cancer patients were collected between January 2007 and December 2018 at National Cancer Centre/National Clinical Research

(c) The Author(s). 2019 Open Access This article is distributed under the terms of the Creative Commons Attribution 4.0 International License (http://creativecommons.org/licenses/by/4.0/), which permits unrestricted use, distribution, and 
Centre for Cancer/Cancer Hospital, Chinese Academy of Medical Sciences and Peking Union Medical College. The inclusion criteria included: [1] older than 80 years old; [2] treated by laparoscopic or open surgery for colorectal cancer. The exclusion criteria were as follows: [1] emergency surgery for reasons such as intestinal obstruction, bleeding or perforation; [2] double primary cancers; [3] treated by palliative surgery; [4] treated by neoadjuvant therapy before surgery. All patients were treated by colorectal surgeons with more than 20 years of surgical experience, and all enrolled patients underwent radical surgery. Besides, written informed consent was obtained from each patient included in the study.

\section{Clinical data collection}

In this study, clinical data were collected based on electronic records and included age, gender, body mass index (BMI), preoperative hemoglobin (HGB), preoperative albumin, American Society of Anesthesiologists (ASA) score, comorbidities, previous abdominal surgery, tumor location, tumor differentiation, and tumor nodes metastasis (TNM) stage. Besides, the perioperative outcomes were also collected including the surgical outcomes, pathological outcomes, and the postoperative recovery. The surgical outcomes included the duration of operation, intraoperative blood loss, blood transfusion, intraoperative complication, postoperative complication, mortality, and intensive care unit (ICU) stay. The pathological outcomes included the retrieved lymph node, tumor size, perineural invasion, vascular invasion, and positive circumferential resection margin (CRM). Postoperative recovery included time to first flatus, time to oral feeding, and postoperative hospital days. The parameters of the postoperative recovery were all calculated based on the end of the operation. Postoperative complications were defined according to the ClavienDindo classification [13], including wound infection, anastomosis leakage, ileus, urosepsis, pneumonia, pelvic abscess, arrhythmia, pleural effusion, delayed gastric emptying, and bacteremia.

\section{Survival outcomes collection}

After surgery, all patients received a follow-up survey every 3-6 months in the first 3 years by outpatient visits. In these 3 years, the patients were diagnosed by physical and laboratory examinations including biomarkers (CEA and CA-199) at each visit, CT scans of the chest, abdomen, and pelvis at every half year, and complete colonoscopy at each year. After the first 3 years, the patients received follow-up survey every $6-12$ months by outpatient visits or telephone until the death of the patients due to recurrence and metastasis of colorectal cancer or December 31, 2018. Based on this follow-up survey, the data about the 5-year overall survival (OS) and diseasefree survival (DFS) were collected.

\section{Statistical analysis \\ The SPSS}

.0 for Windows (IBM Corp, Armonk, NY, USA) was used for data analysis in this study. According to the operation type, patients were divided into laparoscopy and open group. Quantitative data were analyzed by the Mann-Whitney $\mathrm{U}$ test and presented as mean \pm standard deviation $(\bar{x} \pm S D)$. Categorical data were analyzed by the Chi-squared test and presented as frequency and percentage. Propensity score matching (PSM) was carried out by logistic regression to reduce the effects of selection bias in these 2 groups. The matching ratio was 1 : 1 , and the covariates included age, gender, BMI, preoperative HGB level, preoperative albumin level, ASA class, comorbidity, previous abdominal surgery, tumor location, tumor differentiation, and TNM stage. The Kaplan-Meier method was performed to calculate the survivals of the patients treated with different operation types in the 2 groups, and the differences of the survival outcomes (OS and DFS) were compared by a log-rank test. The statistically significant variables in univariate analysis were subsequently tested by multivariate analysis through a Cox-regression model, and the effect of each variable was assessed by the Hazard ratio (HR) and 95\% confidence interval $(95 \% \mathrm{CI})$. All tests were twosided, and the $P$ value less than 0.05 was considered to indicate statistical significance.

\section{Results}

\section{Clinical and pathological characteristics}

Three-hundreds and 13 patients were enrolled in the study. Among them, 93 marched pairs were selected through propensity scoring. The clinical and pathological characteristics before and post matching groups were as shown in Table 1 . Before matching, there were significant differences in aspects of BMI, preoperative HGB, preoperative albumin, ASA, comorbidity, tumor location, differentiation $(P<0.05)$ between the open group and laparoscopic group.

Before matching, the open group had significantly lower BMI $\left(22.7 \pm 3.3 \mathrm{~kg} / \mathrm{m}^{2}\right.$ vs. $23.7 \pm 3.3 \mathrm{~kg} / \mathrm{m}^{2}, P=$ $0.009)$, preoperative $\mathrm{HGB}(120.0 \pm 19.1 \mathrm{~g} / \mathrm{L}$ vs. $124.5 \pm$ $18.7 \mathrm{~g} / \mathrm{L}, P=0.045)$, and preoperative albumin $(37.2 \pm$ $4.3 \mathrm{~g} / \mathrm{L}$ vs. $40.2 \pm 4.1 \mathrm{~g} / \mathrm{L}, P=0.045)$, significantly higher preoperative ASA scores $(63.6 \%$ vs. $34.7 \%$ ASA III-IV, $P<0.001)$, and less comorbidities than the laparoscopic group $(58.0 \%$ vs. $72.4 \%, P=0.008)$. The primary tumor localization was more frequent in the right and left colon and less frequent in the sigmoid colon and rectum in the open group $(P=0.007)$. There were more patients 
Table 1 Clinical and pathological characteristics of elderly patients with colorectal cancer before and after matching

\begin{tabular}{|c|c|c|c|c|c|c|}
\hline \multirow[t]{2}{*}{ Variables } & \multicolumn{3}{|l|}{ Total cohort } & \multicolumn{3}{|l|}{ Matched cohort } \\
\hline & OPEN $(n=143)$ & $\operatorname{LAP}(n=170)$ & P & OPEN $(n=93)$ & $\operatorname{LAP}(n=93)$ & $P$ \\
\hline Age (years, mean $\pm S D$ ) (range) & $82.3 \pm 2.1(80-92)$ & $82 \pm 2.1(80-94)$ & 0.280 & $82.1 \pm 2.1(80-92)$ & $82.0 \pm 2.2(80-94)$ & 0.814 \\
\hline Gender & & & 0.445 & & & 0.655 \\
\hline Male & $91(63.6 \%)$ & $101(59.4 \%)$ & & $56(60.2 \%)$ & $53(57 \%)$ & \\
\hline Female & $52(36.4 \%)$ & $69(40.6 \%)$ & & $37(39.8 \%)$ & $40(43 \%)$ & \\
\hline $\mathrm{BMI}\left(\mathrm{kg} / \mathrm{m}^{2}\right.$, mean $\left.\pm \mathrm{SD}\right)($ range $)$ & $\begin{array}{l}22.7 \pm 3.3(15.8- \\
33.8)\end{array}$ & $\begin{array}{l}23.7 \pm 3.3(15.6- \\
34.1)\end{array}$ & 0.009 & $\begin{array}{l}23.4 \pm 3.0(15.8- \\
33.8)\end{array}$ & $\begin{array}{l}23.2 \pm 3.3(16.8- \\
34.1)\end{array}$ & 0.703 \\
\hline Preoperative HGB (g/L, mean $\pm \mathrm{SD}$ ) (range) & $\begin{array}{l}120.0 \pm 19.1(49- \\
165)\end{array}$ & $\begin{array}{l}124.5 \pm 18.7(62- \\
161)\end{array}$ & 0.045 & $\begin{array}{l}120.2 \pm 19.6(49- \\
165)\end{array}$ & $\begin{array}{l}121.5 \pm 19.2(62- \\
161)\end{array}$ & 0.645 \\
\hline $\begin{array}{l}\text { Preoperative albumin ( } \mathrm{g} / \mathrm{L} \text {, mean } \pm \mathrm{SD} \text { ) } \\
\text { (range) }\end{array}$ & $\begin{array}{l}37.2 \pm 4.3(26.8- \\
46.2)\end{array}$ & $\begin{array}{l}40.2 \pm 4.1(29.1- \\
46.8)\end{array}$ & $<0.001$ & $\begin{array}{l}38.4 \pm 4.0(29.5- \\
46.2)\end{array}$ & $\begin{array}{l}38.9 \pm 4.0(29.1- \\
46.2)\end{array}$ & 0.409 \\
\hline ASA score & & & $<0.001$ & & & 0.378 \\
\hline$|-| \mid$ & $52(36.4 \%)$ & $111(65.3 \%)$ & & $47(50.5 \%)$ & $53(57 \%)$ & \\
\hline||$I-I V$ & $91(63.6 \%)$ & $59(34.7 \%)$ & & $46(49.5 \%)$ & $40(43 \%)$ & \\
\hline Comorbidity & & & 0.008 & & & 0.761 \\
\hline Yes & $83(58.0 \%)$ & $123(72.4 \%)$ & & $60(64.5 \%)$ & $58(62.4 \%)$ & \\
\hline No & $60(42.0 \%)$ & $47(27.6 \%)$ & & $33(35.5 \%)$ & $35(37.6 \%)$ & \\
\hline Previous abdominal surgery & & & 0.456 & & & 0.721 \\
\hline Yes & $30(21.0 \%)$ & $30(17.6 \%)$ & & 19 (20.4\%) & $21(22.6 \%)$ & \\
\hline No & $113(79.0)$ & $140(82.4)$ & & $74(79.6)$ & $72(77.4)$ & \\
\hline Tumor location & & & 0.007 & & & 0.698 \\
\hline Right colon & $51(35.7 \%)$ & $39(23 \%)$ & & $32(34.4 \%)$ & 31 (33.3\%) & \\
\hline Left colon & $10(6.9 \%)$ & $4(2.3 \%)$ & & $7(7.5 \%)$ & $4(4.3 \%)$ & \\
\hline Sigmoid colon & $31(21.7 \%)$ & $42(24.7 \%)$ & & $21(22.6 \%)$ & 19 (20.4\%) & \\
\hline Rectum & $51(35.7 \%)$ & $85(50 \%)$ & & $33(35.5 \%)$ & $39(42 \%)$ & \\
\hline Tumor differentiation & & & 0.029 & & & 0.895 \\
\hline Poor & $29(20.3 \%)$ & $45(26.5 \%)$ & & $23(24.7 \%)$ & $24(25.8 \%)$ & \\
\hline Median & 105 (73.4\%) & $123(72.4 \%)$ & & $67(72 \%)$ & $67(72 \%)$ & \\
\hline High & $9(6.3 \%)$ & $2(1.1 \%)$ & & $3(3.3 \%)$ & $2(2.1 \%)$ & \\
\hline TNM stage* & & & 0.213 & & & 0.860 \\
\hline । & $8(5.6 \%)$ & $12(7.1 \%)$ & & $8(8.6 \%)$ & $10(10.8 \%)$ & \\
\hline$\|$ & $45(31.5 \%)$ & $43(25.3 \%)$ & & $30(32.2 \%)$ & 27 (29.0\%) & \\
\hline III & $83(58.0 \%)$ & $112(65.8 \%)$ & & $53(57.0 \%)$ & $55(59.1 \%)$ & \\
\hline IV & $7(4.9 \%)$ & $3(1.8 \%)$ & & $2(2.2 \%)$ & $1(1.1 \%)$ & \\
\hline Preoperative CEA (ng/mL) & & & & & & 0.503 \\
\hline$\leq 5$ & $102(71.3 \%)$ & $133(78.2 \%)$ & 0.159 & $67(72 \%)$ & $71(76.3 \%)$ & \\
\hline$>5$ & 41 (28.7\%) & $37(21.8 \%)$ & & $26(28 \%)$ & $22(23.7 \%)$ & \\
\hline
\end{tabular}

OPEN open surgery; LAP laparoscopic surgery; BMI body mex index; HGB hemoglobin; ASA American Society of Anesthesiologists; TNM tumor nodes metastasis; CEA carcinoembryonic antigen; SD standard deviation; * evaluated based on 7th edition of AJCC

with poor tumor differentiation in the laparoscopic group than the open group $(26.5 \%$ vs. $20.3 \%, P=0.029)$.

After matching, the laparoscopic group and open group were well balanced in aspects of age, gender, BMI, preoperative HGB, preoperative albumin, ASA score, comorbidity, previous abdominal surgery, tumor location, tumor differentiation, TNM stage, and preoperative CEA.

\section{Short-term outcomes}

The short-term outcomes, including the surgical outcomes, pathological outcomes, and postoperative recovery, in matched cohorts were as shown in Table 2. There was a significant difference in aspects of intraoperative blood loss and postoperative complication between the two groups. The laparoscopic group had 
Table 2 Perioperative outcomes of 186 elderly patients with colorectal cancer in matched cohorts

\begin{tabular}{|c|c|c|c|}
\hline Variables & OPEN $(n=93)$ & $\operatorname{LAP}(n=93)$ & $P$ \\
\hline \multicolumn{4}{|l|}{ Surgical outcome } \\
\hline Duration of operation (min, mean \pm SD) (range) & $149.1 \pm 53.9(45-350)$ & $161.2 \pm 55.3(65-380)$ & 0.064 \\
\hline Intraoperative blood loss (mL, mean \pm SD) (range) & $108.1 \pm 78.5(10-400)$ & $50.9 \pm 44.9(10-200)$ & $<0.001$ \\
\hline Blood transfusion & $21(22.6 \%)$ & $15(16.1 \%)$ & 0.265 \\
\hline Intraoperative complication & $0(0 \%)$ & $1(1.1 \%)$ & 1.000 \\
\hline Postoperative complication & $25(26.9 \%)$ & $10(10.8 \%)$ & 0.005 \\
\hline Wound infection & $9(9.7 \%)$ & $1(1.1 \%)$ & 0.009 \\
\hline Anastomosis leakage & $4(4.3 \%)$ & $2(2.2 \%)$ & 0.678 \\
\hline lleus & $5(5.4 \%)$ & $2(2.2 \%)$ & 0.441 \\
\hline Uroschesis & $1(1.1 \%)$ & $1(1.1 \%)$ & 1.000 \\
\hline Pneumonia & $3(3.2 \%)$ & $2(2.2 \%)$ & 1.000 \\
\hline Pelvic abscess & $0(0 \%)$ & $1(1.1 \%)$ & 1.000 \\
\hline Arrhythmia & $3(3.2 \%)$ & $1(1.1 \%)$ & 1.000 \\
\hline Pleural effusion & $2(2.1 \%)$ & $0(0 \%)$ & 0.477 \\
\hline Delayed gastric emptying & $4(4.3 \%)$ & $1(1.1 \%)$ & 0.365 \\
\hline Bacteremia & $1(1.1 \%)$ & $0(0 \%)$ & 1.000 \\
\hline \multicolumn{4}{|l|}{ Postoperative complication (ClavienDindo classification) } \\
\hline$|-| \mid$ & $16(17.2 \%)$ & $6(6.5 \%)$ & 0.023 \\
\hline III-V & $9(9.7 \%)$ & $4(4.3 \%)$ & 0.150 \\
\hline Mortality & $0(0 \%)$ & $0(0 \%)$ & - \\
\hline ICU staying & $13(13.9 \%)$ & $7(7.5 \%)$ & 0.156 \\
\hline \multicolumn{4}{|l|}{ Pathological outcome } \\
\hline Retrieved lymph node (mean \pm SD) (range) & $17.2 \pm 9.1(1-55)$ & $20.3 \pm 10.5(5-58)$ & 0.030 \\
\hline Tumor size & & & 0.378 \\
\hline$<5 \mathrm{~cm}$ & $46(49.5 \%)$ & $52(55.9 \%)$ & \\
\hline$\geq 5 \mathrm{~cm}$ & 47 (50.5\%) & $41(44.1 \%)$ & \\
\hline Perineural invasion & $22(23.7 \%)$ & $18(19.4 \%)$ & 0.475 \\
\hline Vascular invasion & $28(30.1 \%)$ & $24(25.8 \%)$ & 0.513 \\
\hline Positive CRM & $1(1.1 \%)$ & $0(0 \%)$ & 0.316 \\
\hline Postoperative recovery & & & \\
\hline
\end{tabular}

$O P$ open surgery; LAP laparoscopic surgery; CRM circumferential resection margin

significantly lower intraoperative blood loss $(50.9 \pm 44.9$ $\mathrm{mL}$ vs. $108.1 \pm 78.5 \mathrm{~mL}, P<0.001)$ and lower occurrence of postoperative complication $(10.8 \%$ vs. $26.9 \%, P=$ 0.005). According to the Clavien Dindo classification, the incidence of grade I-II complications in the laparoscopic group was significantly higher $(17.2 \%$ vs. $6.5 \%$, $P=0.023$ ). The most common morbidity in the open group was wound infection in 9 patients (9.7\%), followed by ileus in 5 patients (5.4\%), anastomosis leakage in 4 patients $(4.3 \%)$, and delayed gastric emptying in 4 patients $(4.3 \%)$. In the laparoscopic group, the most common morbidities were anastomosis leakage in 2 patients (2.2\%), ileus in 2 patients (2.2\%) and pneumonia in 2 patients (2.2\%). No patient died during the operation. For the pathological outcome, the retrieved lymph node was significantly higher in the laparoscopic group (20.3 \pm 10.5 days vs. $17.2 \pm 9.1$ days, $P=0.030$ ). Time to first flatus $(4.5 \pm 1.6$ days vs. $5.5 \pm 2.1$ days, $P=0.001)$, time to oral feeding ( $4.8 \pm 2.2$ days vs. $5.9 \pm 2.5$ days, $P=0.003$ ), and postoperative hospital stay $(9.6 \pm 3.3$ days vs. $12.2 \pm$ 5.5 days, $P<0.001)$ were all significantly lower in the laparoscopic group.

\section{Survival analysis}

The mean follow-up period in the matched cohort was 37.4 months (range, 5-122 mouths; open group: 45.4 months; laparoscopic group: 29.5 months). During the whole follow-up period, 40 of the 186 patients died $(21.5 \%)$ and 55 of the 186 patients had local recurrence or distant metastasis (29.5\%). In the matched cohort, the 
Kaplan curves showed no statistically significant difference in OS $(P=0.224)$ and DFS $(P=0.230)$ between the two groups. Besides, the 3- and 5-year OS rates in the open group were 79.6 and $63.4 \%$ respectively and those in the laparoscopic group were 83.9 and $73.1 \%$, respectively (Fig. 1 ). In addition, the 3-year DFS and 5-year DFS rates were 66.6 and $53.8 \%$ respectively in the open group, and they were 76.3 and $69.9 \%$ respectively in the laparoscopic group (Fig. 2).

At univariate analysis, CEA level, N stage, TNM stage, perineural invasion, and vascular invasion significantly affected both OS and DFS $(P<0.05)$. According to multivariate analysis, the OS was significantly affected by CEA level (HR: 2.32; 95\% CI, 1.26-4.98; $P=0.022$ ), TNM stage (HR: 9.82; 95\% CI, 3.15-83.55; $P=0.002$ ) and perineural invasion (HR: 1.57; 95\% CI: 1.15-3.21; $P=0.041$ ). Besides, DFS was significantly affected by the CEA level (HR:1.77; 95\% CI:1.29-4.15; $P=0.038$ ), TNM stage (HR:9.67; 95\% CI:3.18-79.30; $P=0.012$ ), and the perineural invasion (HR:2.09; 95\% CI:1.59-5.32; $P=$ 0.020) (Table 3).

\section{Discussion}

According to this study, in patients older than 80 years old with colorectal cancer, laparoscopic surgery has better short-term outcomes than the open surgery but there is no significant difference for the long-term survival outcomes, CEA level, III/IV stage, and perineural invasion were all reliable predictor of overall survival and disease-free survival for either laparoscopic or open surgery.
Previous studies had already shown that elderly colorectal cancer patients could also obtain better short-term outcomes through laparoscopic surgery [10, 14-19]. In the current study, it was found that the laparoscopic surgery could significantly reduce the intraoperative blood loss and postoperative complication. According to previous report, reduction of blood loss could reduce the stress reaction of surgery and further greatly reduce the incidence of postoperative complications, hence, the reduction of blood loss could effectively improve the postoperative recovery of patients [20]. Besides, among the postoperative complication, the laparoscopic surgery could significantly decrease the incidence of grade I-II complication such as wound infection compared to the open surgery. Moreover, laparoscopic surgery could significantly increase the number of the retrieved lymph node. This was possibly attributed to clear and magnified visualization under laparoscopy, and was consistent with the report of Yang et al. which showed that the laparoscopic could significantly increase the number of retrieved lymph nodes for the early distal gastric cancer [12]. Previous studies had revealed the advantages of laparoscopic surgery about the faster recovery [21-24]. Vignali et al. had reported laparoscopic surgery could significantly decrease the time to first flatus, the time to liquid diet, and hospital stay [23]. Consistent with the above reports, the current study found that compared with the open group, the laparoscopic surgery could significantly reduce the time to flatus, time to oral feeding, and postoperative hospital stay. Overall, the above findings reflected that

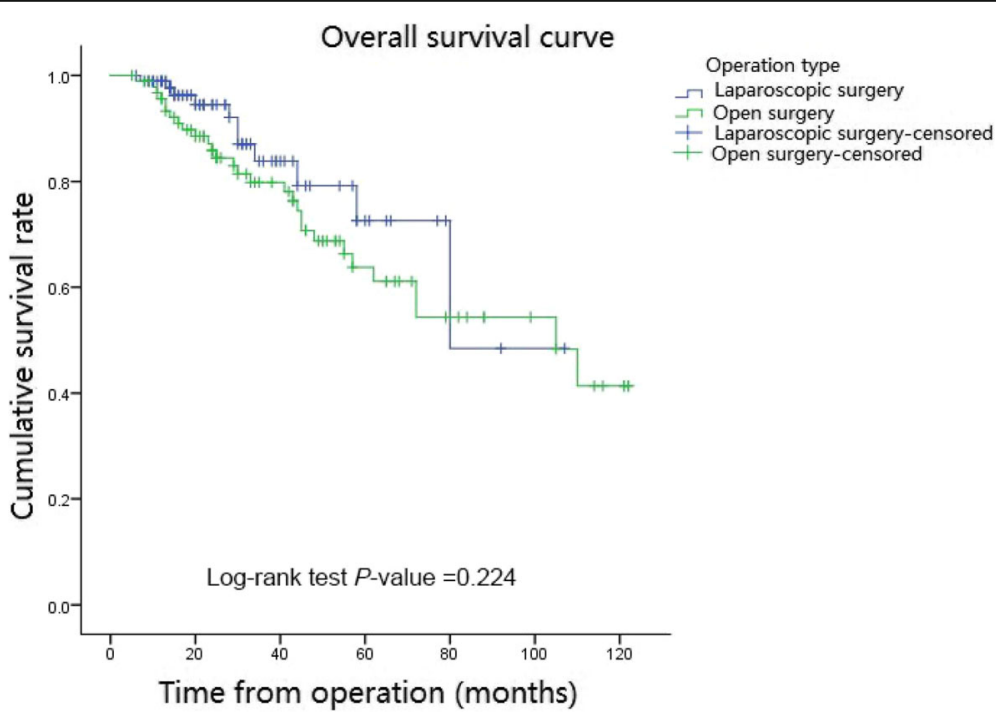

Fig. 1 Overall Survival curve in matched cohort of laparoscopic and open groups. In the matched cohort, in the laparoscopic group, 3- year and 5-year Overall survival rates were 83.9 and $73.1 \%$ respectively and they were 79.6 and $63.4 \%$ respectively in the open group. There was no significant difference between the laparoscopic and open groups $(P=0.224)$ 


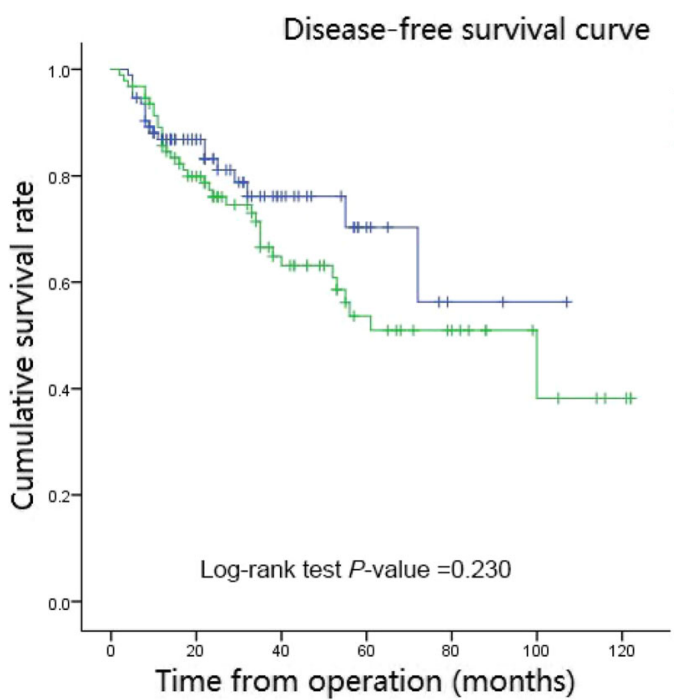

Fig. 2 Disease-free curve in matched cohort of laparoscopic and open group. In the matched cohort, in the laparoscopic group, 3- year and 5year disease-free survival rates were 76.3 and $69.9 \%$ respectively and they were 66.6 and $53.8 \%$ respectively in the open group. There was no significant difference between the laparoscopic and open groups $(P=0.230)$

Table 3 Univariate and multivariate analysis for overall survival and disease-free survival in matched cohorts

\begin{tabular}{|c|c|c|c|c|c|c|c|c|}
\hline \multirow[t]{3}{*}{ Variables } & \multicolumn{4}{|l|}{ Overall survival } & \multicolumn{4}{|l|}{ Disease-free survival } \\
\hline & \multicolumn{2}{|l|}{ Univariate analysis } & \multicolumn{2}{|c|}{ Multivariate analysis } & \multicolumn{2}{|l|}{ Univariate analysis } & \multicolumn{2}{|c|}{ Multivariate analysis } \\
\hline & $\mathrm{HR}(95 \% \mathrm{Cl})$ & $P$ & $\mathrm{HR}(95 \% \mathrm{Cl})$ & $P$ & HR $(95 \% \mathrm{Cl})$ & $P$ & HR $(95 \% \mathrm{Cl})$ & $P$ \\
\hline Gender: male/female & $1.11(0.60-2.08)$ & 0.739 & & & $0.72(0.42-1.23)$ & 0.225 & & \\
\hline Operative type: open/lap.* & $1.30(0.76-2.15)$ & 0.224 & & & $1.41(0.80-2.47)$ & 0.230 & & \\
\hline$C E A>5$ & $1.53(1.11-3.58)$ & 0.008 & $2.32(1.26-4.98)$ & 0.022 & $2.35(1.85-4.39)$ & $<0.001$ & $1.77(1.29-4.15)$ & 0.038 \\
\hline ASA: I-II/III-IV & $0.93(0.73-1.94)$ & 0.811 & & & $1.25(0.64-2.13)$ & 0.410 & & \\
\hline Comorbidity & $1.32(0.78-2.33)$ & 0.222 & & & $1.06(0.53-1.51)$ & 0.639 & & \\
\hline Tumor size $\geq 5 \mathrm{~cm}$ & $1.49(0.97-2.95)$ & 0.156 & & & $1.14(0.63-1.97)$ & 0.443 & & \\
\hline \multicolumn{9}{|l|}{ N stage } \\
\hline No & Reference & - & Reference & - & Reference & - & Reference & - \\
\hline N1 & $3.60(1.56-8.30)$ & 0.003 & $0.36(0.05-2.77)$ & 0.324 & $3.93(1.94-7.96)$ & $<0.001$ & $0.45(0.06-3.46)$ & 0.444 \\
\hline N2 & $14.37(6.11-33.82)$ & $<0.001$ & $1.03(0.16-1.59)$ & 0.854 & $12.25(5.91-25.43)$ & $<0.001$ & $1.46(0.20-2.30)$ & 0.714 \\
\hline TNM stage: |-|I/III-IV & $6.43(2.93-14.10)$ & $<0.001$ & $9.82(3.15-83.55)$ & 0.002 & $6.26(3.22-12.18)$ & $<0.001$ & $9.67(3.18-79.30)$ & 0.012 \\
\hline Differentiation & $0.61(0.31-1.21)$ & 0.157 & & & & & & \\
\hline Poor & Reference & - & & & Reference & - & Reference & - \\
\hline Median & $0.63(0.32-1.25)$ & 0.189 & & & $0.80(0.52-1.47)$ & 0.286 & & \\
\hline High & $0.72(0.40-1.53)$ & 0.279 & & & $0.75(0.45-1.33)$ & 0.248 & & \\
\hline Perineural invasion & $4.24(2.21-8.14)$ & $<0.001$ & $1.57(1.15-3.21)$ & 0.041 & $2.12(1.42-4.25)$ & 0.002 & $2.09(1.59-5.32)$ & 0.020 \\
\hline Vascular invasion & $2.72(1.44-5.14)$ & 0.002 & $1.23(0.61-2.47)$ & 0.075 & $1.78(1.02-3.09)$ & 0.041 & $1.63(0.88-2.95)$ & 0.133 \\
\hline Retrieved lymph node & $0.85(0.71-1.72)$ & 0.533 & & & $0.79(0.51-1.43)$ & 0.273 & & \\
\hline Postoperative complication & $0.96(0.84-1.98)$ & 0.857 & & & $1.32(0.70-2.41)$ & 0.396 & & \\
\hline
\end{tabular}


the laparoscopic surgery had better short-term outcomes in the treatment of elderly patients with colorectal cancer than the open surgery.

Few studies reported data regarding long-term outcomes of laparoscopic surgery [25, 26]. In 2015, Hinoi et al. reported that there was no significant difference for octogenarian patients with rectal or colon cancer in 3-year overall survival, disease-free survival, and cancerspecific survival between laparoscopic and open groups [26]. Likewise, in 2016, Moon et al. reported that the laparoscopic surgery was without any significant difference for the 3- and 5-year overall survival, and 3-year and 5-year recurrence-free survival compared to the open surgery [25]. In this study, no difference in the 3year and 5 -year OS rates $(P=0.224)$ and in 3 - year and 5 -year DFS rates $(P=0.230)$ were observed between the open and laparoscopic surgery. Besides, it is noteworthy that the 3-year and 5-year OS rates, and 3- year and 5year DFS rates of patients in the laparoscopic group were generally higher than the open group. The 5-year DFS rate in the laparoscopic group was even higher than that in the open group by more than $10 \%$. This difference might be due to the difference in the number of dissected lymph node between the open group and the laparoscopic group. Hence, although there was no significant difference in survival outcomes between the two surgical methods, the laparoscopic surgery in elderly patients with colorectal cancer might achieve better survival outcomes than the open surgery.

Prognostic factors affecting the survival of colorectal cancer patients have been previously reported [27-30]. Huh et al. had reported that both preoperative CEA level, TNM stage, and vascular or neural invasion were independent prognostic factors for the overall survival and disease-free survival in potentially curative colorectal cancer [30]. Besides, Tsai et al. reported the perineural invasion as a significant prognostic factor for postoperative relapse for stage II colorectal cancer undergoing radical resection [27]. Consistently with the previous studies, in this study, it was found that CEA level, III/IV stage, and perineural invasion were all independent predictors for the overall survival and the disease-free survival of elderly patients with colorectal cancer.

This study has the limitations of any retrospective study. However, selection bias was reduced by propensity score matching through logistic regression. Multicenter large-scale prospective studies are needed to further confirm whether laparoscopic treatment is more suitable for elderly patients with colorectal cancer in terms of short-term and survival outcomes. Cutoff values for CEA level, III/IV stage, and perineural invasion were not evaluated in this study, so large-scale studies are necessary to determine specific valid cutoff values for CEA level, III/IV stage, and perineural invasion.

\section{Conclusions}

Laparoscopic surgery showed better results than the open surgery in short-term outcomes. CEA level, III/IV stage, and perineural invasion were all reliable predictor of overall survival and disease-free survival for the treatment of laparoscopic surgery and open surgery for elderly Chinese patients over 80 years old with colorectal cancer.

\section{Abbreviations \\ ASA: American Society of Anesthesiologists; BMI: body mass index; CEA: carcinoembryonic antigen; Cl: confidence interval; CRM: circumferential resection margin; DFS: disease-free survival; HGB: hemoglobin; HR: hazard ratio; ICU: intensive care unit; OS: on overall survival; PSM: Propensity score matching; TME: total mesorectal excision; TNM: tumor nodes metastasis}

\section{Acknowledgements \\ Not applicable.}

\section{Consent to publication}

Not Applicable.

\section{Authors' contributions}

Contributions: (I) conception and design: JWL, SCZ, XWW; (II) administrative support: JWL, ZXZ2; (III) provision of study materials or patients: SCZ, QL, ZXZ1; (IV) collection and assembly of data: HTZ and ZXZ1; ( $)$ data analysis and interpretation: SCZ. All authors read and approved the final manuscript.

\section{Funding}

This work is supported by the Beijing Hope Run Special Fund of Cancer Foundation of China (LC2017A19) and the Capital Health Research and Development of Special (2016-2-4022). The funding was mainly used for the data collection in current study, and the study designation, analysis, interpretation of data and writing were also almost carried out without the supporting of the funding

\section{Availability of data and materials}

The datasets generated and/or analysed during the current study are not publicly available due to the data is confidential patient data but are available from the corresponding author on reasonable request.

\section{Ethics approval and consent to participate}

The ethics committee of the National Cancer Center/Cancer Hospital, Chinese Academy of Medical Sciences and Peking Union Medical College approved this study.

\section{Competing interests}

The authors declare that they have no competing interests.

Received: 15 May 2019 Accepted: 29 August 2019

Published online: 14 September 2019

\section{References}

1. Ferlay J, Soerjomataram I, Dikshit R, et al. Cancer incidence and mortality worldwide: sources, methods and major patterns in GLOBOCAN 2012. Int J Cancer. 2015;136(5):E359-86.

2. Athanasiou CD, Robinson J, Yiasemidou M, et al. Laparoscopic vs open approach for transverse colon cancer. A systematic review and metaanalysis of short and long term outcomes. Int J Surg. 2017;41:78-85.

3. Parker JM, Feldmann TF, Cologne KG. Advances in laparoscopic colorectal surgery. Surg Clin North Am. 2017;97(3):547-60.

4. Reza MM, Blasco JA, Andradas E, et al. Systematic review of laparoscopic versus open surgery for colorectal cancer. Br J Surg. 2006;93(8):921-8.

5. Guillou PJ, Quirke P, Thorpe H, et al. Short-term endpoints of conventional versus laparoscopic-assisted surgery in patients with colorectal cancer (MRC CLASICC trial): multicentre, randomised controlled trial. Lancet. 2005;365(9472):1718-26.

6. Fleshman J, Sargent DJ, Green E, et al. Laparoscopic colectomy for cancer is not inferior to open surgery based on 5-year data from the COST study group trial. Ann Surg. 2007;246(4):655-62. 
7. Jayne DG, Thorpe HC, Copeland J, et al. Five-year follow-up of the Medical Research Council CLASICC trial of laparoscopically assisted versus open surgery for colorectal cancer. Br J Surg. 2010;97(11):1638-45.

8. Bagshaw PF, Allardyce RA, Frampton CM, et al. Long-term outcomes of the australasian randomized clinical trial comparing laparoscopic and conventional open surgical treatments for colon cancer: the Australasian laparoscopic Colon Cancer study trial. Ann Surg. 2012;256(6):915-9.

9. Frasson M, Braga M, Vignali A, et al. Benefits of laparoscopic colorectal resection are more pronounced in elderly patients. Dis Colon Rectum. 2008;51(3):296-300.

10. Stocchi L, Nelson H, Youngfadok TM, et al. Safety and advantages of laparoscopic vs. open colectomy in the elderly: matched-control study. Dis Colon Rectum. 2000;43(3):326-32.

11. Stewart BT, Stitz RW, Lumley JW. Laparoscopically assisted colorectal surgery in the elderly. Br J Surg. 1999;86(7):938-41.

12. Yang ZF, Wu DQ, Wang JJ, et al. Short-and long-term outcomes following laparoscopic vs open surgery for pathological T4 colorectal cancer: 10 years of experience in a single center. World J Gastroenterol. 2018;24(1):76-86.

13. Clavien PA, Barkun J, de Oliveira ML, et al. The Clavien-Dindo classification of surgical complications: five-year experience. Ann Surg. 2009;250(2):187-96

14. Chautard J, Alves A, Zalinski S, et al. Laparoscopic colorectal surgery in elderly patients: a matched case-control study in 178 patients. J Am Coll Surg. 2008;206(2):255-60

15. Person B, Cera SM, Sands DR, et al. Do elderly patients benefit from laparoscopic colorectal surgery? Surg Endosc. 2008;22(2):401-5.

16. Tan KY, Konishi F, Kawamura YJ, et al. Laparoscopic colorectal surgery in elderly patients: a case-control study of 15 years of experience. Am J Surg. 2011;201(4):531-6.

17. Fiscon V, Portale G, Frigo F, et al. Laparoscopic resection of colorectal cancer: matched comparison in elderly and younger patients. Tech Coloprocto. 2010;14(4):323-7.

18. Vallribera Valls F, Landi F, Espín Basany E, et al. Laparoscopy-assisted versus open colectomy for treatment of colon cancer in the elderly: morbidity and mortality outcomes in 545 patients. Surg Endosc. 2014;28(12):3373-8.

19. Grailey K, Markar SR, Karthikesalingam A, et al. Laparoscopic versus open colorectal resection in the elderly population. Surg Endosc. 2013;27(1):19-30.

20. Zhang X, Wu Q, Gu C, et al. Comparison of short and long-time outcome between laparoscopic and conventional open multivisceral resection for primary T4b colorectal cancer. Asian J Surg. 2019:42(1):401-8.

21. Feng $\mathrm{B}$, Zheng $\mathrm{MH}$, Mao ZH, et al. Clinical advantages of laparoscopic colorectal cancer surgery in the elderly. Aging Clin Exp Res. 2006;18(3):191-5

22. She WH, Poon TC, Fan JK, et al. Outcome of laparoscopic colectomy for cancer in elderly patients. Surg Endosc. 2013;27(1):308-12.

23. Vignali A, Di Palo S, Tamburini A, et al. Laparoscopic vs. open colectomies in octogenarians: a case-matched control study. Dis Colon Rectum. 2005; 48(11):2070-5:

24. Akiyoshi T, Kuroyanagi H, Oya M, et al. Short-term outcomes of laparoscopic rectal surgery for primary rectal Cancer in elderly patients: is it safe and beneficial? J Gastrointest Surg. 2009;13(9):1614-8.

25. Moon SY, Kim S, Lee SY, et al. Laparoscopic surgery for patients with colorectal cancer produces better short-term outcomes with similar survival outcomes in elderly patients compared to open surgery. Cancer Med. 2016;5(6):1047-54.

26. Hinoi T, Kawaguchi Y, Hattori M, et al. Laparoscopic versus open surgery for colorectal cancer in elderly patients: a multicenter matched case-control study. Ann Surg Oncol. 2015;22(6):2040-50.

27. Tsai HL, Cheng KI, Lu CY, et al. Prognostic significance of depth of invasion, vascular invasion and numbers of lymph node retrievals in combination for patients with stage II colorectal cancer undergoing radical resection. J Surg Oncol. 2008:97(5):383-7.

28. Mehrkhani F, Nasiri S, Donboli $K$, et al. Prognostic factors in survival of colorectal cancer patients after surgery. Color Dis. 2009:11(2):157-61.

29. Fujita S, Shimoda T, Yoshimura K, et al. Prospective evaluation of prognostic factors in patients with colorectal cancer undergoing curative resection. J Surg Oncol. 2003;84(3):127-31.

30. Huh JW, Oh BR, Kim HR, et al. Preoperative carcinoembryonic antigen level as an independent prognostic factor in potentially curative colon cancer. J Surg Oncol. 2010;101(5):396-400.

\section{Publisher's Note}

Springer Nature remains neutral with regard to jurisdictional claims in published maps and institutional affiliations.

\section{Ready to submit your research? Choose BMC and benefit from:}

- fast, convenient online submission

- thorough peer review by experienced researchers in your field

- rapid publication on acceptance

- support for research data, including large and complex data types

- gold Open Access which fosters wider collaboration and increased citations

- maximum visibility for your research: over $100 \mathrm{M}$ website views per year

At $\mathrm{BMC}$, research is always in progress.

Learn more biomedcentral.com/submissions 